\title{
Preparation of Poly(ether ether ketone) Dendrimers by the Divergent Method
}

\author{
Atsushi MORIKAWA ${ }^{\dagger}$ and Katsumichi ONO \\ Department of Materials Science, Faculty of Engineering, Ibaraki University, \\ 4-12-1 Nakanarusawa, Hitachi-shi, Ibaraki 316-8511, Japan
}

(Received July 30, 1999)

\begin{abstract}
New highly branched poly(ether ether ketone) dendrimers were synthesized by the divergent approach through aromatic nucleophilic substitution reactions. 3,5-Dimethoxy-4'-(4-fluorobenzoyl)diphenylether, 1, and 1,3,5-tris $[p$-(3,5-dihydroxyphenoxy)phenyl]benzene, G0-OH, were used as a building block and starting core, respectively. The reaction of $\mathbf{1}$ with $\mathbf{G 0}-\mathbf{O H}$ gave the first-generation dendrimer (G1-OMe), which possessed 12 methoxy groups on the periphery. After the methoxy groups were converted to hydroxy groups by treatment with pyridine hydrochloride, the resultant phenol functionality $(\mathbf{G 1}-\mathbf{O H})$ was allowed to react with 1 to yield the second-generation dendrimer (G2-OMe) which possessed 24 methoxy groups. By repeating these procedures G3-OMe dendrimer and G3-OH dendrimer possessing 48 methoxy and hydroxy groups, respectively, on the periphery were obtained. ${ }^{1} \mathrm{H}$ and ${ }^{13} \mathrm{C}$ NMR spectra were consistent with the structures of these dendrimers. Molecular weights and molecular weight distribution determined by gel permeation chromatography indicated that the dendrimers possessed remarkably narrow molecular weight distribution. Analysis was made of these structurally unambiguous dendrimers by matrix-assisted laser desorption ionization time of flight (MALDI-TOF) mass spectroscopy. The characteristics of these dendrimers, Gn-OMe and $\mathbf{G n}-\mathbf{O H}$, such as solubility and thermal properties were compared.
\end{abstract}

KEY WORDS Poly(ether ether ketone) Dendrimers / Divergent Method / 3,5-Dimethoxy-4'-(4-fluorobenzoyl)diphenylether / 1,3,5-Tris[ $p$-(3,5-dihydroxyphenoxy)phenyl]benzene / Aromatic Nucleophilic Substitution Reactions /

Dendrimers ${ }^{1-4}$ are highly branched regular molecules, whose geometrical structures are usually prepared by repeating stepwise reaction. There have been divergent ${ }^{5}$ and convergent ${ }^{6}$ methods for the synthesis of dendrimers. In the divergent method, the preparation starts from a core molecule, which possesses two or more reactive groups. A building block contains one functional group to connect with reactive groups of the core and two or more protected reactive group, the same as those of the core. In the convergent method, a compound possessing only one reactive group is used as the starting molecule, and the building block possesses two or more connecting points and one protected reactive group. In both cases, after the reactive points on the starting molecule and building block are connected, the protected reactive points are released. Connection of building blocks followed by deprotection are repeated until the molecules have grown to desired size. By the divergent method, dendrimers such as poly(amido-amine), ${ }^{5,7-11}$ polyamine, ${ }^{12}$ polyether, ${ }^{13,14}$ polysiloxane, ${ }^{15,16}$ polyamide ${ }^{17-20}$ poly(carbosilane), ${ }^{21-23}$ poly(carbosilazane $)^{24}$ and poly(alkyl hydrocarbon) ${ }^{25}$ have been synthesized. The convergent method has been used to synthesize polyether, ${ }^{6,26-29}$ polyester, ${ }^{30-32}$ polyamide, ${ }^{33}$ polysiloxane, ${ }^{34}$ poly(phenylene), ${ }^{35}$ poly(ether ketone), ${ }^{36,37}$ poly (arylacetylene) ${ }^{38-42}$ poly(arylamine $)^{43}$ and aliphatic polyether. ${ }^{44}$ The orthogonal approach, ${ }^{45-47}$ wherein the protection or deprotection steps are eliminated by use of two different building blocks, was demonstrated in the convergent method. Their size could be accurately controlled $^{48,49}$ and functional groups could be introduced into the periphery using such a stepwise reaction. ${ }^{50-58}$ Dendrimers with well-defined controlled structure are considered promising as functional supramolecules. Am-

\footnotetext{
${ }^{\dagger}$ To whom correspondence should be addressed.
}

phiphilic dendrimers, with relatively nonpolar cores and hydrophilic outer surfaces, have been applied as micelles. ${ }^{59-63}$

However, the divergent method appears more advantageous to introduce functional groups into the periphery than the convergent method because it allows exterior functionalization of the dendrimers subsequent to dendrimer synthesis. One more step for the introduction of the functional groups is required after dendrimer synthesis in the convergent method. A new process, the conversion of the benzyl ester groups to the carboxyl groups, was required in the convergent synthesis of polyester. ${ }^{30}$ It was thought to be impossible to introduce functional groups into the periphery in author's convergent synthesis of poly(ether ketone) because highly reactive aluminum chloride was used in the conversion of the protected methoxy group to the reactive hydroxy group. ${ }^{36,37}$

This study describes a divergent synthetic root to dendritic poly(ether ether ketone)s possessing methoxy or hydroxy groups at the periphery, where methoxy groups are used as protective form for hydroxy groups, and dendritic molecules are grown by a reaction between the hydroxy groups and aromatic fluorides activated by carbonyl groups in the para position. All dendrimers prepared are characterized with respect to molecular weight using MALDI-TOF. The characteristics of the dendrimers such as solubility and thermal properties are discussed on the basis of the contribution of the end methoxy or hydroxy groups, on the periphery.

\section{RESULTS AND DISCUSSION}

The key steps in the synthesis of poly(ether ether ketone) dendrimers are the formation of covalent bonds for extension to dendrimers and deprotection to release reactive points. These steps are similar to those of poly- 

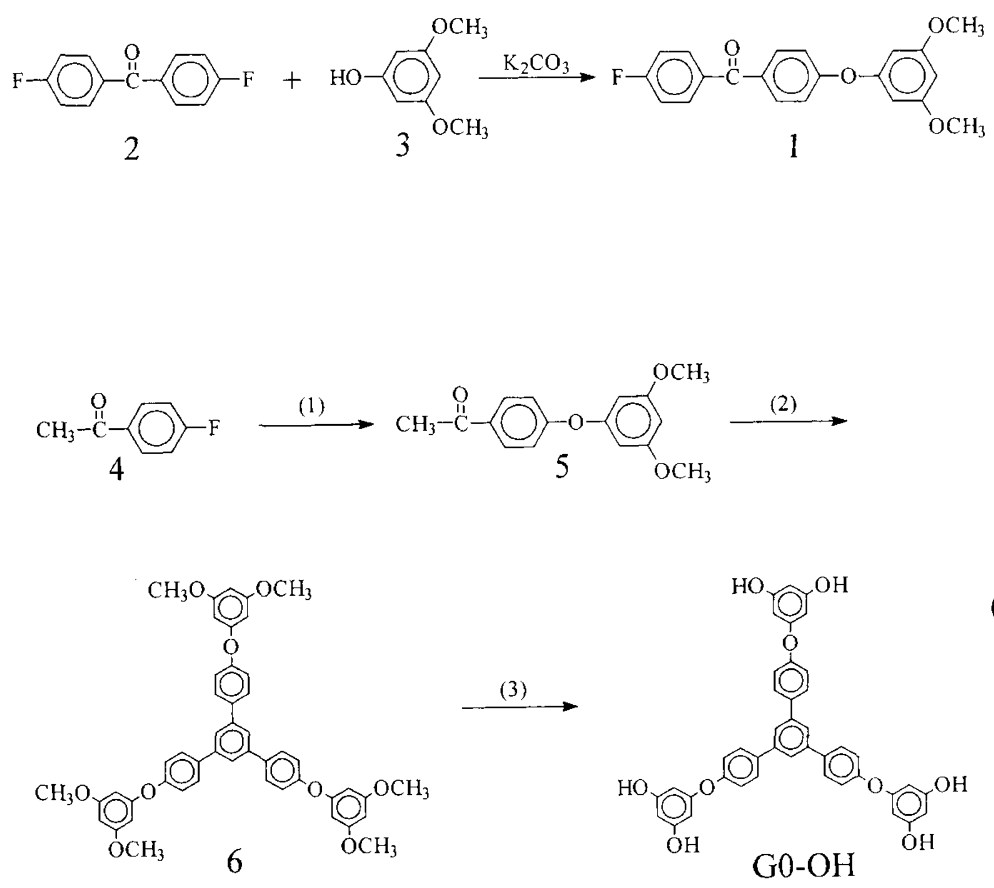

$$
\begin{array}{lll}
\text { (1) } 3, \mathrm{~K}_{2} \mathrm{CO}_{3} & \text { (2) } \mathrm{CF}_{3} \mathrm{SO}_{3} \mathrm{H} & \text { (3) pyridine } \mathrm{HCl}
\end{array}
$$

(ether ketone) dendrons, ${ }^{36,37}$ as reported, and the former step is the formation of aromatic ether by reaction between phenol and aromatic fluoride activated by carbonyl group. Secondly, phenol is protected by the methyl group, which can be cleaved by the treatment with pyridine hydrochloride. ${ }^{64,65}$ Thus, 3,5-dimethoxy-4' -(4-fluorobenzoyl)diphenylether, $\mathbf{1}$, was used as the building block for the present dendrimer, which possessed two methoxy groups and one aromatic fluoride activated by carbonyl group. Building block, 1, was synthesized by the reaction between 4,4'-difluorobenzophenone, $\mathbf{2}$, and 3,5-dimethoxyphenol, 3 , as shown in eq 1 , and was purified by fractional distillation.

As the starting core, 1,3,5-tris( $p$-(3,5-dihydroxyphenoxy)phenyl)benzene, G0-OH, was used. G0-OH was synthesized in three steps starting from 4-fluoroacetophenone, 4 , and 3 as shown in eq 2 . After the reaction of 4 with $\mathbf{3}$, the acetyl group of the resultant compound, $\mathbf{5}$, was condensed to 1,3,5-trisphenylbenzene derivative, $\mathbf{6}$, by acid catalysis. ${ }^{66}$ The cleavage of methoxy group in $\mathbf{6}$ afforded the starting core, G0-OH. The overall yield of the three steps was $58 \%$.

A general synthetic procedure for the poly(ether ether ketone) dendrimers is shown in Scheme 1. First, reaction of G0-OH with 1 in the presence of potassium carbonate yielded the first-generation dendrimer, G1-OMe. The methoxy group of G1-OMe was cleaved by the treatment with pyridine hydrochloride at $240^{\circ} \mathrm{C}$ to give G1-OH. Further reaction of G1-OH with 1 yielded the second-generation dendrimers, G2-OMe, under similar conditions for the preparation of G1-OMe. After conversion of G2-OMe to G2- OH, one more repeat of these procedures afforded G3-OMe and G3- $-\mathbf{O H}$ possessing 48 methoxy and hydroxy groups, respectively, on the pe- riphery were prepared. The obtained dendrimers were colorless powders, which were purified by silica gel column chromatography. The final isolated yields of G1OMe, G2-OMe, and G3-OMe were $92 \%, 83 \%$, and $62 \%$, respectively, and those of G1-OH, G2-OH, and G3-OH were $95 \%, 91 \%$, and $87 \%$, respectively.

The growth and purity of these dendrimers were confirmed by GPC (Figure 1) and MALDI-TOF (Figure 2). MALDI-TOF was used to obtain definite evidence for the structure of the present poly(ether ether ketone) dendrimers. This method provides highly accurate mass determinations for nonvolatile intact molecular ions, and has been demonstrated by recent investigation of dendrimers with excellent results. ${ }^{21,40,63,66-71}$

In GPC curves, the crude higher generation dendrimers (G2-OMe and G3-OMe) showed relatively broad molecular weight distribution because of the presence of the lower molecular weight impurities. In the MALDITOF mass spectra of the crude G3-OMe, signals for the lower molecular weight impurities were observed besides abundant peaks for the dendrimers, and as differences between these observed signals were 332 aum, which corresponded to the $-\mathrm{C}_{6} \mathrm{H}_{4} \mathrm{COC}_{6} \mathrm{H}_{4} \mathrm{OC}_{6} \mathrm{H}_{3}(\mathrm{OMe})_{2}$ unit, the formation of these low molecular weight impurities were regarded to due to incomplete reaction between $\mathbf{G}-\mathbf{O H}$ and $\mathbf{1}$. In the MALDI-TOF mass spectra of the purified dendrimers, molecular ion peaks occurred at $\mathrm{m} / \mathrm{z}$ which agreed very closely with calculated values, and all spectra confirmed that the products were of very high purity and monodispersed. That no signals for impurities were observed in the spectra of $\mathbf{G n}-\mathbf{O H}$ suggests that no side reaction occurrs even during deprotective treatment at high temperatures.

Figure 3 shows the ${ }^{1} \mathrm{H}$ NMR spectra of the dendrimers. 

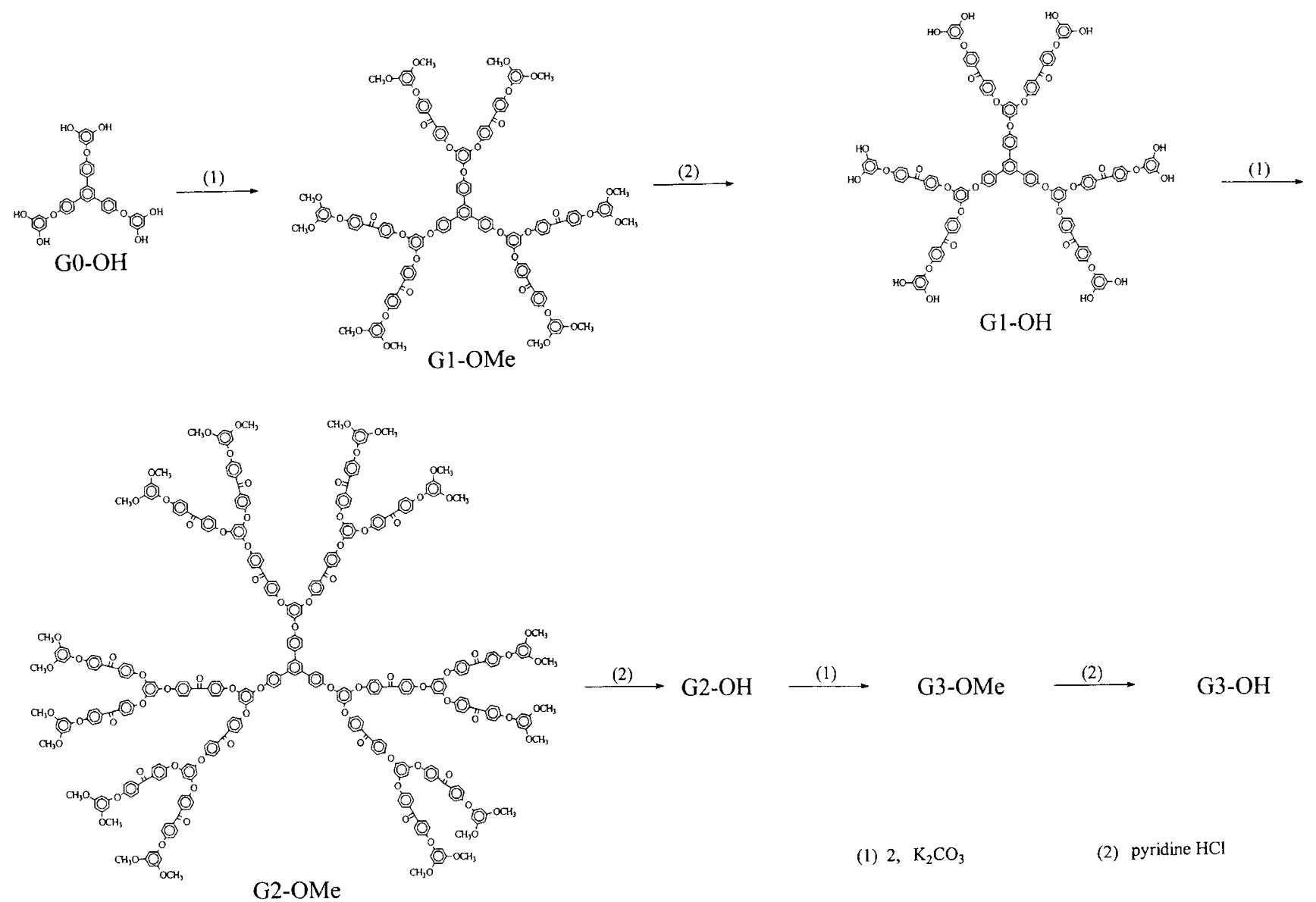

Scheme 1.

In the ${ }^{1} \mathrm{H}$ NMR spectra of $\mathbf{G n}-\mathbf{O H}$, signals of the methoxy protons being present in $\mathbf{G n}$-OMe disappeared, while signals of the hydroxy group appeared. The signals of aromatic protons could be classified as signals of protons on the exterior 1,3,5-trisubstituted aromatic rings with two methoxy groups or two hydroxy groups (a), protons on the 1,3,5-trisubstituted aromatic rings with three phenoxy groups in the interior of the molecules (b), protons on the meta-position of the carbonyl groups (c), protons on the ortho-position of the carbonyl groups (d), and protons on 1,3,5-trisphenylbenzene ring ascribed to the starting core, G0-OH (e). The obtained ratios of these protons agreed with calculated values.

${ }^{13} \mathrm{C}$ NMR spectra of these dendrimers were complicated due to the presence of many signals. Thus, only the regions $195-190 \mathrm{ppm}$ and $110-95 \mathrm{ppm}$ of $\mathbf{G n}-\mathbf{O H}$, the most distinctive, are shown in Figure 4. Resonance for the carbonyl carbons is seen in the former region. Resonance for the carbons bonded to hydrogen atoms on the 1,3,5-trisubstituted aromatic rings is seen in the latter region. Resonance attributed to the trisubstituted aromatic rings originated in the starting core, G0-OH, near $105 \mathrm{ppm}$, those attributed to the trisubstituted aromatic rings located at the exterior near 99 and $98 \mathrm{ppm}$, and those attributed to the other trisubstituted aromatic rings located at the interior near $106 \mathrm{ppm}$. As generation number increased, the signals for the units originated in the starting core. $\mathbf{G n}-\mathbf{O H}$, decreased in the intensity compared to the corresponding resonance for other units.

The solubility of these dendrimers was remarkably in- fluenced by groups at the periphery. Dendrimers possessing the methoxy groups at the periphery, Gn-OMe, were soluble in various organic solvents such as amide solvents, dimethyl sulfoxide, tetrahydrofuran, methylene chloride, chloroform and benzene. Dendrimers possessing the hydroxy groups at the periphery, Gn-OH, insoluble in non-polar solvents such as methylene chloride, chloroform and benzene, and soluble in amides solvent, dimethyl sulfoxide, tetrahydrofuran, methanol, and surprisingly, aqueous $\mathrm{KOH}$ or $\mathrm{NaOH}$ solution. The solubility of G1-OH, G2-OH, and G3-OH, in $1.0 \mathrm{~g}$ of 1 $\mathrm{M}$ aqueous $\mathrm{NaOH}$ solution were $90 \mathrm{mg}, 70 \mathrm{mg}$, and 25 $\mathrm{mg}$, respectively. Therefore, the solubility of the higher generation dendrimer was lower. These dendrimers, $\mathbf{G n}$ $-\mathbf{O H}$, were not soluble in water.

The viscosity of these dendrimers was measured. Figures 5 and 6 show the relationships between reduced viscosity $\eta \mathrm{sp} / C$ and concentration $C$ in tetrahydrofuran and $1 \mathrm{M}$ aqueous $\mathrm{NaOH}$ solution, respectively. Gn-OMe could not be measured in $1 \mathrm{M}$ aqueous $\mathrm{NaOH}$ solution due to the insolubility. The reduced viscosity of these dendrimers was independent on concentration, and that of higher generation dendrimers was higher. These dendrimers were thus not associated one another in solution. The viscosity of $\mathbf{G n}-\mathbf{O H}$ in tetrahydrofuran was higher than that of $\mathbf{G n}-\mathbf{O M e}$ in the same solvent and that of $\mathbf{G n}-\mathbf{O H}$ in $1 \mathrm{M}$ aqueous $\mathrm{NaOH}$ solution. This higher viscosity of $\mathbf{G n}-\mathbf{O H}$ in tetrahydrofuran may be due to solvation of tetrahydrofuran to hydroxy groups, leading extension of the molecule. 


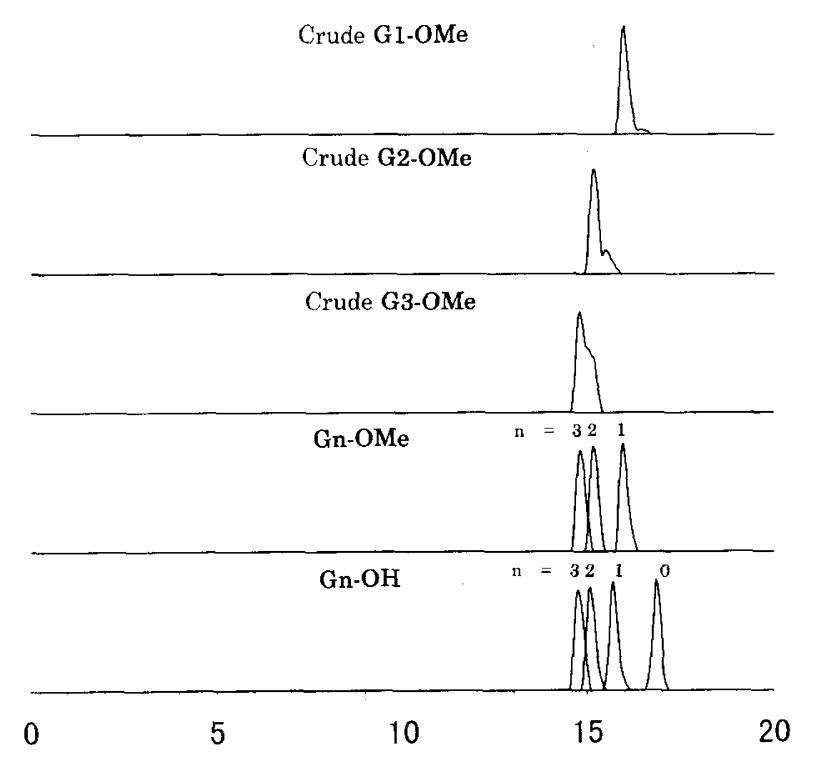

Elution Volume $(\mathrm{ml})$

Figure 1. GPC curves of crude and purified poly(ether ether ketone) dendrimers.

Thermal behavior of these dendrimers was evaluated by differential scanning calorimetry (DSC). These dendrimers seemed to be non-crystalline and only glass transition temperature $\left(T_{\mathrm{g}}\right)$ was observed. $T_{\mathrm{g}} \mathrm{s}$ of $\mathbf{G 1}-$ OMe, G2-OMe, and G3-OMe were 75, 95 and $101^{\circ} \mathrm{C}$, respectively, and higher generation dendrimers showed higher $T_{\text {gs. }}$ G1-OH, G2-OH, and G3-OH appeared at 143,145 , and $144{ }^{\circ} \mathrm{C}$, respectively, and much higher $T_{\mathrm{g}} \mathrm{s}$ than those of $\mathbf{G n}-\mathbf{O M e}$, which were thought to be due to interactions such as hydrogen-bonding. In the case of Gn-OH $T_{\mathrm{g}}$ s were independent of generation in contrast to the case of $\mathbf{G n}$-OMe. This suggests that interactions between the peripheral groups affect $T_{\mathrm{g}} \mathrm{s}$ of dendrimers more dramatically than the movement of chains. Such interactions seemed negligible in the case of $\mathbf{G n}-\mathbf{O M e}$. $T_{\mathrm{gs}}$ of the present dendrimers, $\mathbf{G n}-\mathbf{O H}$, were more independent of generation in comparison with the previous polyether ${ }^{72}$ and poly(carbosilazane $)^{24}$ dendrimers which had the same hydroxy groups at the periphery. The formation of a network structure may thus occur among dendrimers, $\mathbf{G n}-\mathbf{O H}$, by the hydrogen-bonding between not only the hydroxy groups but also the hydroxy groups and the carbonyl groups, not present in previous dendrimers. Such hydrogen-bonding was comfirmed in the IR spectra of $\mathbf{G n}-\mathbf{O H}$. In the IR spectra of $\mathbf{G n}-\mathbf{O H}$, two carbonyl absorption bands at 1650 and $1630 \mathrm{~cm}^{-1}$, assigned to the free carbonyl groups and the hydrogenbonding carbonyl groups, respectively, were observed, but in those of Gn-OMe, only one carbonyl band was observed at $1650 \mathrm{~cm}^{-1}$.

\section{EXPERIMENTAL}

${ }^{1} \mathrm{H}$ and ${ }^{13} \mathrm{C}$ NMR spectra and IR spectra were recorded on a JNM-GSX-400 FT-NMR spectrometer and Shimadzu IR 435 spectro-photometer, respectively. Gel permeation chromatography (GPC) was performed using a
G1-OMe

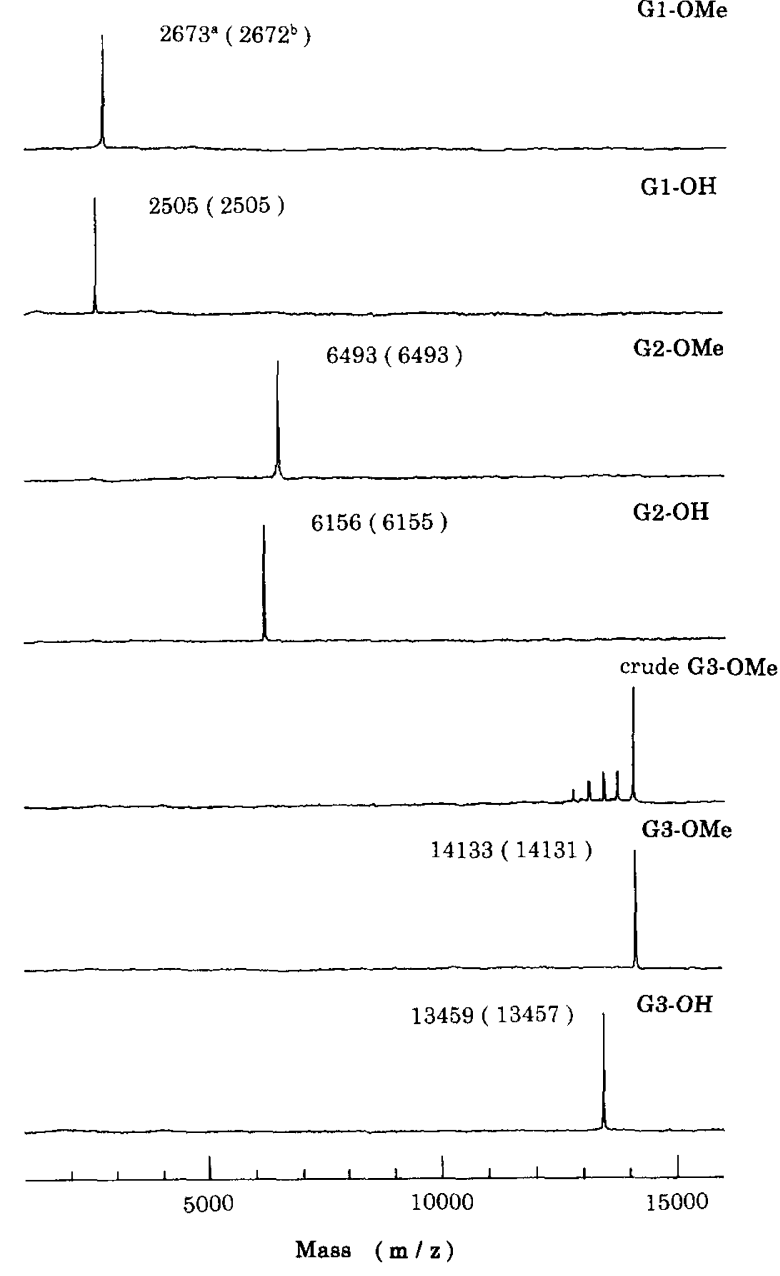

Figure 2. MALDI-TOF mass spectra and molecular mass data of poly(ether ether ketone) dendrimers : Gn-OMe, Gn-OH ( $\boldsymbol{n}=1,2$, 3 ), and crude G3-OMe. ${ }^{a}$ Measured mass. ${ }^{b}$ Calculated mass.

Polymer Laboratories analytical column, PL gel $5 \mu$ MIXED-C, and tetrahydrofuran as eluent. Specific viscosity $\eta$ sp was measured at various concentrations using Ubbelohde-type capillary viscometer in tetrahydrofuran and $1 \mathrm{M}$ aqueous $\mathrm{NaOH}$ solution at $30^{\circ} \mathrm{C}$. Differential scanning calorimetry (DSC) was performed with a Shimadzu DSC-60. Measurements of DSC were made at a heating rate of $10^{\circ} \mathrm{C} \mathrm{min}-1$ in nitrogen. MALDI-TOF spectra were recorded on a Shimadzu/Kratos Kompact MALDI II equipped with a $337 \mathrm{~nm}$ nitrogen laser. For dendrimers except G3-OMe, sample preparation was as follows. The solution of the analyte $(5 \mathrm{mg})$, the matrix (20 mg), and trifluoroacetic acid (one drop) in tetrahydrofuran (THF) (1 mL) was prepared and a $1 \mu \mathrm{l}$ of this matrix/sample solution was transferred to a stainless steel sample plate via an automatic pipette. The measurement was performed in positive ion mode using 2,5dihydroxybenzoic acid as the matrix. In the case of G3OMe after the solution of the matrix and trifluoroacetic acid in THF was transferred to the stainless steel sample plate, the solution of G3-OMe in THF was transferred to the same position in the plate. $o$-[ $(p$-Hydroxyphenyl)azo]-benzoic acid was used as the matrix.

3,5-Dimethoxy-4'-(4-fluorobenzoyl)diphenylether (1). In a flask, a mixture of $21.82 \mathrm{~g}(0.1 \mathrm{~mol})$ of $4,4^{\prime}$-difluoro- 


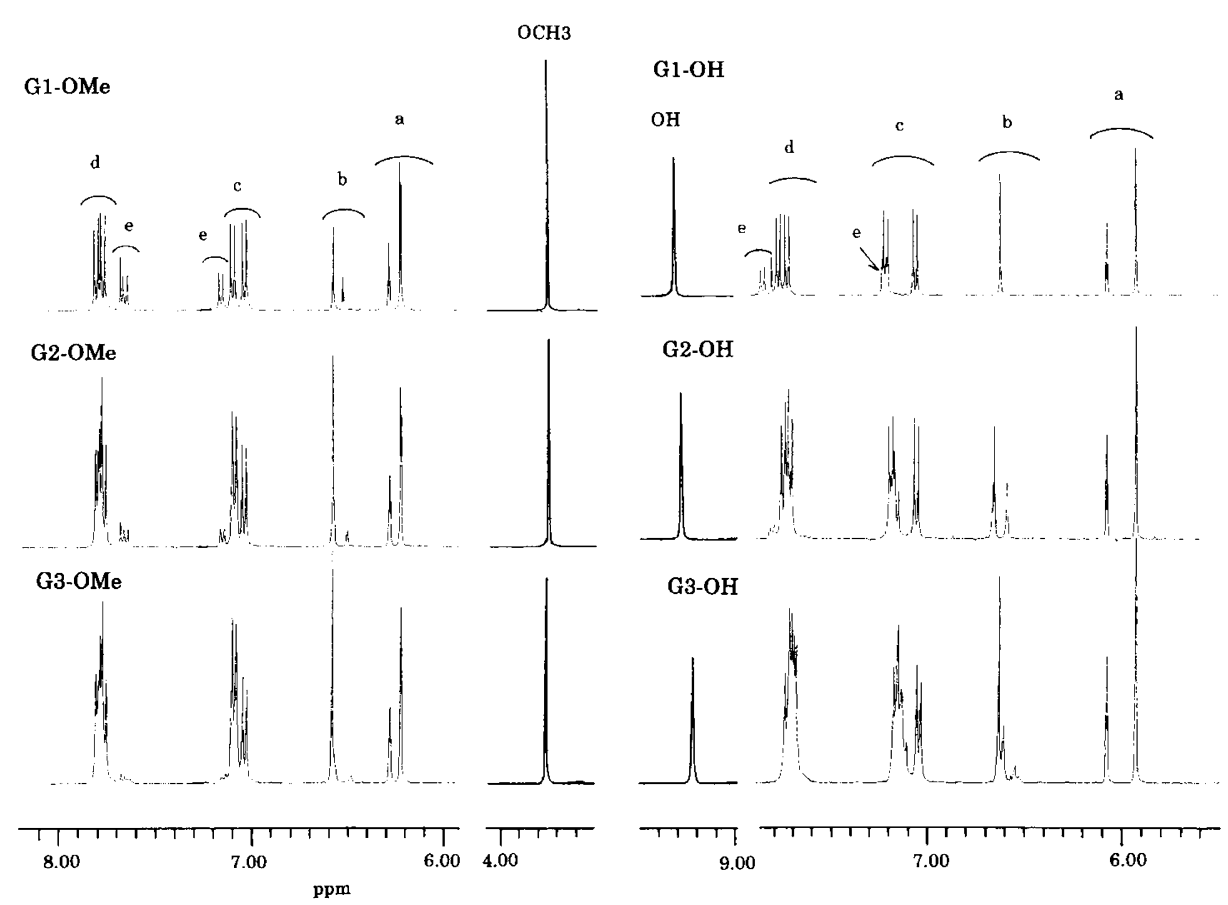

Figure 3. ${ }^{1} \mathrm{H}$ NMR spectra of $\mathbf{G} \boldsymbol{n}-\mathbf{O M e}$ and $\mathbf{G} \boldsymbol{n}-\mathbf{O H}(\boldsymbol{n}=1,2,3)$.

benzophenone, $15.42 \mathrm{~g}(0.1 \mathrm{~mol})$ of 3,5-dimethoxyphenol, $13.82 \mathrm{~g}(0.10 \mathrm{~mol})$ of potassium carbonate, $50 \mathrm{~mL}$ of toluene, and $90 \mathrm{~mL}$ of $N, N$-dimethylacetamide was stirred at $130^{\circ} \mathrm{C}$ for $1 \mathrm{~h}$. The temperature was raised to $160^{\circ} \mathrm{C}$ and water formed during the reaction was removed as an azeotrope with toluene. The reaction mixture was stirred at this temperature for $1.5 \mathrm{~h}$. After the reaction was complete, the mixture was cooled to about $80^{\circ} \mathrm{C}$ and the solvent was evaporated under reduced pressure of 15 -20 torr. The residue was washed with $300 \mathrm{~mL}$ of water and extracted twice with $200 \mathrm{~mL}$ of methylene chloride. After the combined extract was dried over anhydrous magnesium sulfate, the solvent was evaporated. The residue was distilled three times under reduced pressure (Glass tube oven) by fractional distillation to give pure $\mathbf{1}$. Yield : $18.52 \mathrm{~g}(53 \%) . \mathrm{Mp}: 53-54^{\circ} \mathrm{C} . \mathrm{Bp}: 260^{\circ} \mathrm{C}$ ( 1 torr $)$. IR (KBr) : 2940, 1640, 1600, 1230, $1160 \mathrm{~cm}^{-1} .{ }^{1} \mathrm{H}$ NMR $\left(\mathrm{CDCl}_{3}, \mathrm{ppm}\right): \delta 3.77(\mathrm{~s}, 6 \mathrm{H}), 6.25(\mathrm{~d}, 2 \mathrm{H}, J=2.2 \mathrm{~Hz})$, $6.31(\mathrm{t}, 1 \mathrm{H}, d=2.2 \mathrm{~Hz}), 7.07(\mathrm{~d}, 2 \mathrm{H}, J=8.8 \mathrm{~Hz}), 7.15(\mathrm{~m}$, $2 \mathrm{H}), 7.79(\mathrm{~d}, 2 \mathrm{H}, J=8.8 \mathrm{~Hz}), 7.82(\mathrm{~m}, 2 \mathrm{H}) .{ }^{13} \mathrm{C} \mathrm{NMR}$ $\left(\mathrm{CDCl}_{3}, \mathrm{ppm}\right): \delta 55.46,96.72,98.52,115.37(\mathrm{~d}, J=22.3$ $\mathrm{Hz}), 117.49,131.95,132.21,132.37(\mathrm{~d}, J=8.0 \mathrm{~Hz}), 134$. $06(\mathrm{~d}, J=3.2 \mathrm{~Hz}), 157.32,161.21,161.78,165.18$ (d, $J=$ 234.3 Hz), 193.96. Anal . Calcd for $\mathrm{C}_{21} \mathrm{H}_{17} \mathrm{O}_{4} \mathrm{~F}: \mathrm{C}, 71.58$; $\mathrm{H}, 4.86$. Found : C, $71.43 ; \mathrm{H}, 4.88$.

3,5-Dimethoxy-4' -acetyl-diphenylether (5). In a flask, a mixture of $13.81 \mathrm{~g}(0.1 \mathrm{~mol})$ of 4-fluoroacetophenone, $15.42 \mathrm{~g}(0.1 \mathrm{~mol})$ of 3,5-dimethoxyphenol, $13.82 \mathrm{~g}(0.10$ $\mathrm{mol}$ ) of potassium carbonate, $30 \mathrm{~mL}$ of toluene, and 60 $\mathrm{mL}$ of $N, N$-dimethylacetamide was stirred at $130^{\circ} \mathrm{C}$ for $1 \mathrm{~h}$. The temperature was raised to $160^{\circ} \mathrm{C}$ and water formed during the reaction was removed as an azeotrope with toluene. The reaction mixture was stirred at this temperature for $1.5 \mathrm{~h}$. After the reaction was complete, the mixture was cooled to about $80^{\circ} \mathrm{C}$, and the solvent was evaporated under reduced pressure of 15-20 torr. The residue was washed with $300 \mathrm{~mL}$ of water and ex- tracted twice with $200 \mathrm{~mL}$ of methylene chloride. After the combined extract was dried over anhydrous magnesium sulfate, the solvent was evaporated. The residue was distilled under reduced pressure to give pure $\mathbf{5}$. Yield : $23.5 \mathrm{~g}(86 \%)$. Bp : $168-170^{\circ} \mathrm{C}$ (1 torr). Mp : $79-$ $80^{\circ} \mathrm{C}$. IR (KBr) : 2940, 1675, 1590, $1235,1155 \mathrm{~cm}^{-1} .{ }^{1} \mathrm{H}$ $\mathrm{NMR}\left(\mathrm{CDCl}_{3}, \mathrm{ppm}\right): \delta 2.55(\mathrm{~s}, 3 \mathrm{H}), 3.76(\mathrm{~s}, 6 \mathrm{H}), 6.40(\mathrm{~d}, 2$ $\mathrm{H}, J=2.2 \mathrm{~Hz}), 6.55\left(\mathrm{t},{ }^{1} \mathrm{H}, d=2.2 \mathrm{~Hz}\right), 7.05(\mathrm{~d}, 2 \mathrm{H}, J=$ $8.8 \mathrm{~Hz}), 7.94(\mathrm{~d}, 2 \mathrm{H}, J=8.8 \mathrm{~Hz}) .{ }^{13} \mathrm{C} \mathrm{NMR}\left(\mathrm{CDCl}_{3}, \mathrm{ppm}\right): \delta$ 26.43, 55.48, 96.78, 98.50, 117.60, 130.54, 132.14, 154.31, 157.05, 161.78, 196.80. Anal. Calcd for $\mathrm{C}_{16} \mathrm{H}_{16} \mathrm{O}_{4}: \mathrm{C}$, $70.58 ; \mathrm{H}, 5.92$. Found : C, 70.62 ; H, 5.99 .

1,3,5-Tris(p-(3,5-dimethoxyphenoxy)phenyl)benzene (6). A mixture of $21.8 \mathrm{~g}(0.08 \mathrm{~mol})$ of 5 and $0.3 \mathrm{~mL}$ of trifluoromethanesulfonic acid in $200 \mathrm{~mL}$ of toluene was refluxed with removal of water through a Dean-Stark trap for about $8 \mathrm{~h}$. After the generation of water stopped, the reaction mixture was cooled to room temperature. The precipitated product was collected by filtration, washed with methanol to remove the trifluoromethanesulfonic acid, dried under vacuum, and twice recrystallized from toluene to give pure 6. Yield : $14.3 \mathrm{~g}(70 \%)$. $\mathrm{Mp}: 224-225^{\circ} \mathrm{C} . \mathrm{IR}(\mathrm{KBr}): 2940,1605,1225,1155,1130$ $\mathrm{cm}^{-1} .{ }^{1} \mathrm{H}$ NMR (CDCl 3, ppm) : $\delta 3.76(\mathrm{~s}, 18 \mathrm{H}), 6.23(\mathrm{~d}, 6$ $\mathrm{H}, J=2.2 \mathrm{~Hz}), 6.25(\mathrm{t}, 3 \mathrm{H}, d=2.2 \mathrm{~Hz}), 7.13(\mathrm{~d}, 6 \mathrm{H}, J=$ $8.8 \mathrm{~Hz}), 7.66(\mathrm{~d}, 6 \mathrm{H}, J=8.8 \mathrm{~Hz}), 7.72(\mathrm{~s}, 3 \mathrm{H}) .{ }^{13} \mathrm{C} \mathrm{NMR}$ $\left(\mathrm{CDCl}_{3}, \mathrm{ppm}\right): \delta 55.47,95.69,97.43,119.49,124.53$, 128.63 , 136.40, 141.73, 156.58, 159.09, 161.69. Anal. Calcd for $\mathrm{C}_{48} \mathrm{H}_{42} \mathrm{O}_{9}$ : C, $75.58 ; \mathrm{H}, 5.55$. Found : C, 75.73 ; $\mathrm{H}, 5.69$.

1,3,5-Tris(p-(3,5-dihydoxyphenoxy)phenyl)benzene (GO -OH). $6(11.4 \mathrm{~g}, 15 \mathrm{mmol})$ was heated together with pyridine hydrochloride $(50 \mathrm{~g})$ at reflux temperature (240 ${ }^{\circ} \mathrm{C}$ ) for about $30 \mathrm{~min}$. After the reaction mixture was homogeneous, it was poured into water $(1000 \mathrm{~mL})$, and extracted twice with $100 \mathrm{~mL}$ of ethyl acetate. The combined extract was dried over anhydrous magnesium sul- 


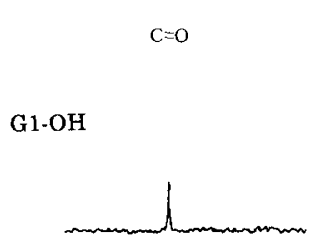

G2-OH

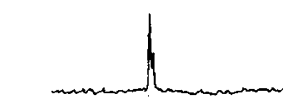

G3-OH

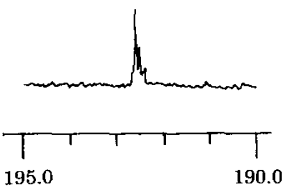

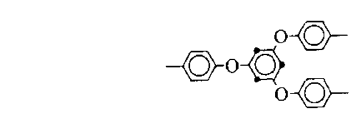

$\mathrm{OCH}_{3}$

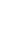

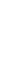




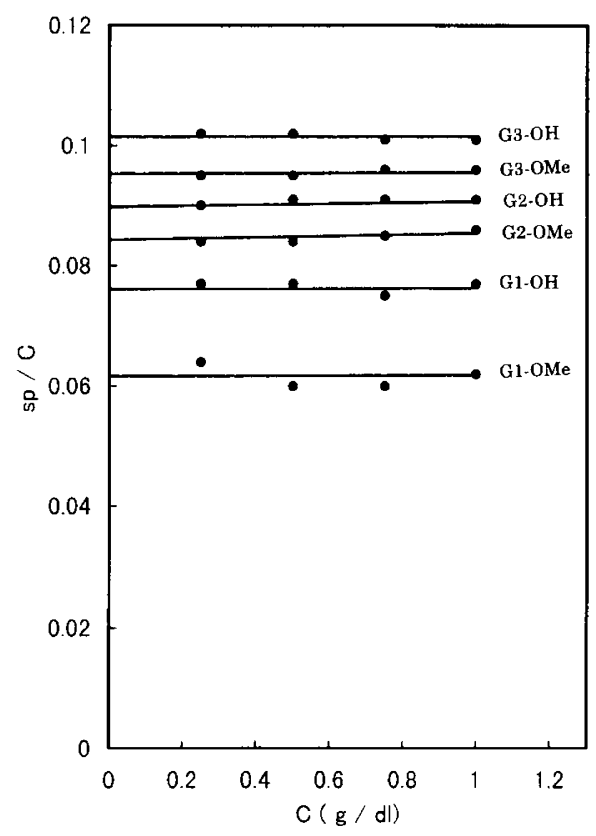

Figure 5. Plots of reduced viscosity $\eta \mathrm{sp} / C$ vs. concentration $C$ of $\mathbf{G n}-\mathbf{O M e}$ and $\mathbf{G n}-\mathbf{O H}(\boldsymbol{n}=1,2,3)$ in tetrahydrofuran.

tate $(15: 1)$. Yield : $5.39 \mathrm{~g}(83 \%)$. IR $(\mathrm{KBr}): 2940,1650$, $1590,1225,1160 \mathrm{~cm}^{-1} .{ }^{1} \mathrm{H}$ NMR $\left(\mathrm{CDCl}_{3}, \mathrm{ppm}\right): \delta 3.75(\mathrm{~s}$, $72 \mathrm{H}), 6.23(\mathrm{~d}, 24 \mathrm{H}, J=2.2 \mathrm{~Hz}), 6.29(\mathrm{t}, 12 \mathrm{H}, d=2.2 \mathrm{~Hz})$, $6.51(\mathrm{t}, 3 \mathrm{H}, d=2.2 \mathrm{~Hz}), 6.58(\mathrm{~m}, 24 \mathrm{H}), 7.05(\mathrm{~d}, 24 \mathrm{H}, J=$ $8.8 \mathrm{~Hz}), 7.10(\mathrm{~m}, 48 \mathrm{H}), 7.16(\mathrm{~d}, 6 \mathrm{H}, J=8.8 \mathrm{~Hz}), 7.66(\mathrm{~d}, 6$ $\mathrm{H}, J=8.8 \mathrm{~Hz}), 7.69(\mathrm{~s}, 3 \mathrm{H}), 7.75-7.83(\mathrm{~m}, 72 \mathrm{H}) .{ }^{13} \mathrm{C}$ $\mathrm{NMR}\left(\mathrm{CDCl}_{3}, \mathrm{ppm}\right): \delta 55.47,96.69,98.47,105.32,105.38$, $106.06,106.22,117.51,117.81,117.98,118.11,120.01$, $124.72,128.86,132.09,132.20,132.26,132.29,132.89$, $133.08,133.35,133.37,137.13,141.54,155.49,157.35$, $158.11,158.33,158.43,159.71,159.87,160.01,160.11$, 161.10, 161.77, 193.94, 194.67. Anal. Calcd for $\mathrm{C}_{408} \mathrm{H}_{294}$ $\mathrm{O}_{81}: \mathrm{C}, 75.48 ; \mathrm{H}, 4.56$. Found : C, $75.43 ; \mathrm{H}, 4.48$.

G2-OH. G2- OH was prepared by the same procedure as that for the synthesis of G1-OH using $4.54 \mathrm{~g}$ $(0.7 \mathrm{mmol})$ of G2-OMe, and $60 \mathrm{~g}$ of pyridine hydrochloride. Pure G2-OH was obtained by silica gel column chromatography by methylene chloride and ethyl acetate $(3: 7)$. Yield : $4.31 \mathrm{~g}(91 \%)$. IR $(\mathrm{KBr}): 3400-3000$, $1650,1590,1227,1160 \mathrm{~cm}^{-1} .{ }^{1} \mathrm{H}$ NMR (DMSO- $\left.d_{6}, \mathrm{ppm}\right)$ : $\delta 5.93(\mathrm{~d}, 24 \mathrm{H}, J=2.2 \mathrm{~Hz}), 6.08(\mathrm{t}, 12 \mathrm{H}, d=2.2 \mathrm{~Hz}), 6.59$ (m, 9H), $6.66(\mathrm{~m}, 18 \mathrm{H}), 7.06(\mathrm{~d}, 24 \mathrm{H}, J=8.8 \mathrm{~Hz}), 7.15-$ $7.22(\mathrm{~m}, 54 \mathrm{H}), 7.69-7.78(\mathrm{~m}, 72 \mathrm{H}), 7.81(\mathrm{~d}, 6 \mathrm{H}, J=8.8$ $\mathrm{Hz}) .{ }^{13} \mathrm{C}$ NMR (DMSO- $\left.d_{6}, \mathrm{ppm}\right): \delta 97.81,98.94,104.88$, $105.02,106.05,106.08,117.26,117.34,117.85,117.94$, $119.43,123.68,128.57,131.48,131.59,131.67,131.73$, $131.76,132.29,132.42,132.49,132.66,136.01,140.54$, $155.02,156.68,157.66,157.75,157.77,158.96,159.10$, $159.16,159.26,159.30,160.40,192.81,192.84$. Anal. Calcd for $\mathrm{C}_{384} \mathrm{H}_{246} \mathrm{O}_{81}: \mathrm{C}, 74.92 ; \mathrm{H}, 4.03$. Found : C, $74.81 ; \mathrm{H}, 3.99$.

Third-Generation Dendrimer (G3-OMe). G3-OMe was prepared by the same procedure as that for the synthesis of G1-OMe using $1.85 \mathrm{~g}(0.3 \mathrm{mmol})$ of $\mathbf{G 2}-\mathbf{O H}$, $3.81 \mathrm{~g}(10.8 \mathrm{mmol})$ of $1,1.49 \mathrm{~g}(10.8 \mathrm{mmol})$ of potassium carbonate, $15 \mathrm{~mL}$ of toluene and $30 \mathrm{~mL}$ of $N, N$-dimethylacetamide. Pure G3-OMe was obtained by silica gel column chromatography beginning with methylene chlo-

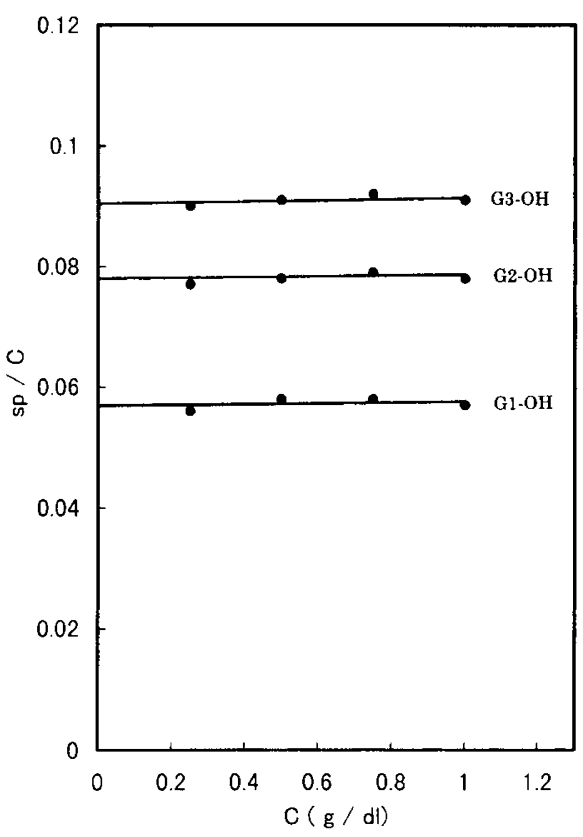

Figure 6. Plots of reduced viscosity $\eta \mathrm{sp} / C$ us. concentration $C$ of $\mathbf{G n}-\mathbf{O H}(\boldsymbol{n}=1,2,3)$ in $1 \mathrm{M} \mathrm{NaOH}$ aqueous solution.

ride and ethyl acetate $(20: 1)$ as eluent and gradually changing to methylene chloride and ethyl acetate $(13: 1)$. Yield : $2.63 \mathrm{~g}(62 \%)$. IR (KBr) : 2940, 1655, 1590, 1225, $1160 \mathrm{~cm}^{-1} .{ }^{1} \mathrm{H} \mathrm{NMR}\left(\mathrm{CDCl}_{3}, \mathrm{ppm}\right): \delta 3.75(\mathrm{~s}, 144 \mathrm{H}), 6.22$ $(\mathrm{d}, 48 \mathrm{H}, J=2.2 \mathrm{~Hz}), 6.28(\mathrm{t}, 24 \mathrm{H}, d=2.2 \mathrm{~Hz}), 6.48(\mathrm{t}, 3 \mathrm{H}$, $d=2.2 \mathrm{~Hz}), 6.58(\mathrm{~m}, 60 \mathrm{H}), 7.04(\mathrm{~d}, 48 \mathrm{H}, J=8.8 \mathrm{~Hz}), 7.06$ $-7.10(\mathrm{~m}, 120 \mathrm{H}), 7.15(\mathrm{~d}, 6 \mathrm{H}, J=8.8 \mathrm{~Hz}), 7.65(\mathrm{~d}, 6 \mathrm{H}, J$ $=8.8 \mathrm{~Hz}), 7.68(\mathrm{~s}, 3 \mathrm{H}), 7.74-7.83(\mathrm{~m}, 168 \mathrm{H}) .{ }^{13} \mathrm{C} \mathrm{NMR}$ $\left(\mathrm{CDCl}_{3}, \mathrm{ppm}\right): \delta 55.48,96.83,98.60,105.32,105.49$, 106.22 , 106.27, 106.30, 117.60, 118.05, 118.16, 118.46, $119.98,124.70,128.88,131.85,132.09,132.17,132.23$, $132.29,133.02,133.18,133.24,133.27,133.53,137.19$, $141.59,155.63,157.51,158.22,158.45,158.48,158.51$, $158.54,159.76,159.87,159.90,159.98,160.06,160.14$, $161.13,161.89,193.75,193.86,193.93$. Anal. Calcd for $\mathrm{C}_{888} \mathrm{H}_{630} \mathrm{O}_{177}: \mathrm{C}, 75.47 ; \mathrm{H}, 4.49$. Found : C, 75.35; $\mathrm{H}$, 4.41 .

G3-OH. G3-OH was prepared by the same procedure as that for the synthesis of G1-OH using $2.11 \mathrm{~g}$ $(0.15 \mathrm{mmol})$ of G3-OMe and $80 \mathrm{~g}$ of pyridine hydrochloride. Pure G3-OH was obtained by silica gel column chromatography by methylene chloride and ethyl acetate $(3: 7)$. Yield : $1.76 \mathrm{~g}(87 \%)$. IR (KBr) : 3400-3000, $1650,1590,1227,1162 \mathrm{~cm}^{-1} .{ }^{1} \mathrm{H}$ NMR (DMSO-d $\left.d_{6}, \mathrm{ppm}\right)$ : $\delta 5.93(\mathrm{~d}, 48 \mathrm{H}, J=2.2 \mathrm{~Hz}), 6.08(\mathrm{t}, 24 \mathrm{H}, d=2.2 \mathrm{~Hz}), 6.55$ $(\mathrm{m}, 9 \mathrm{H}), 6.61(\mathrm{~m}, 18 \mathrm{H}), 6.63(\mathrm{~m}, 36 \mathrm{H}), 7.05(\mathrm{~d}, 48 \mathrm{H}, J=$ $8.8 \mathrm{~Hz}), 7.09-7.20(\mathrm{~m}, 126 \mathrm{H}), 7.65-7.77(\mathrm{~m}, 177 \mathrm{H})$, $9.20(\mathrm{~s}, 48 \mathrm{H}) .{ }^{13} \mathrm{C}$ NMR (DMSO- $\left.d_{6}, \mathrm{ppm}\right): \delta 97.67,98.86$, $104.49,104.69,105.61,105.67,105.74,105.77,117.13$, $117.21,117.67,117.78,119.19,123.96,128.30,131.22$, $131.35,131.43,132.01,132.35,132.42,132.65,135.81$, $140.35,154.88,156.60,157.50,157.53,157.63,157.66$, $157.68,158.69,158.86,158.91,158.96,159.00,159.10$, $159.40,160.19,192.45,192.52,192.60$. Anal. Calcd for $\mathrm{C}_{840} \mathrm{H}_{534} \mathrm{O}_{177}: \mathrm{C}, 74.96 ; \mathrm{H}$, 4.00. Found : $\mathrm{C}, 75.01 ; \mathrm{H}$, 4.03 .

Acknowledgment. The authors thank Prof. Hiroshi 
Mase and Mr. Toshio Tanabe of Ibaraki University for equipment and assistance in measuring MALDI-TOF spectra.

\section{REFERENCE AND NOTES}

1. D. A. Tomalia, A. M. Naylor, and W. A. Goddard, Angew. Chem., Int. Ed. Engl., 29, 138 (1990).

2. D. A. Tomalia and H. D. Durst, Top. Curr. Chem., 165, 193 (1993).

3. D. A. Tomalia and H. D. Durst, in "Supramolecular Chemistry I-Directed Synthesis Molecular Recognition", E. Weber, Ed., Topics in Current Chemistry Vol. 165 ; Springer-Verlag, Berlin, Heiderberg, 1993, pp 193-313.

4. G. R. Newkome, "Advances in Dendritic Macromolecules", JAI Press, Greenwich, CT, 1993. Y. H. Kim, Adv. Mater., 4, 764 (1992).

5. D. A. Tomalia, H. Baker, J. Dewald, M. Hall, G. Kallos, S. Martin, J. Ryder, and P. Smith, Polym. J. 17, 117 (1985).

6. C. J. Hawker and J. M. J. Frechet. J. Chem. Soc., Chem. Commun., 1010 (1990).

7. D. A. Tomalia, H. Baker, J. Dewald, M. Hall, G. Kallos, S. Martin, J. Roeck, J. Ryder, and P. Smith, Macromolecules, 19, 2466 (1986).

8. D. A. Tomalia, M. Hall, and D. M. Hedstrand, J. Am. Chem. Soc. 109, 1601 (1987).

9. D. A. Tomalia, V. Berry, M. Hall, and D. M. Hedstrand, Macromolecules, 20,1164 (1987).

10. A. M. Naylor, W. A. Goggard, III, G. E. Keifer, and D. A. Tomalia, J. Am. Chem. Soc., 111, 2339 (1989).

11. M. C. Moreno-Bundi, G. Orellana, N. J. Turro, and D. A. Tomalia, Macromolecules, 23, 910 (1990).

12. E. Buhleier, W. Wehner, and F. Vogtle, Synthesis, 155 (1978).

13. A. B. Padia, H. K. Hall, Jr., and D. A. Tomalia, J. Org. Chem., 52, 5305 (1987).

14. O. Haba, K. Haga, M. Ueda, O. Morikawa, and H. Konishi, Chem. Mater., 11, 427 (1999).

15. H. Uchida, Y. Kabe, K. Yoshino, A. Kawamata, T. Tsumuyama, and S. Masamune, J. Am. Chem. Soc., 112, 7077 (1990).

16. A. Morikawa, M. Kakimoto, and Y. Imai, Macromolecules, 24, 3469 (1991).

17. G. R. Newkome, R. K. Behera, C. N. Moorefield, and G. R. Baker, J. Org. Chem., 56, 7162 (1991).

18. G. R. Newkome and X. Lin, Macromolecules, 24, 1443 (1991).

19. G. R. Newkome, J. K. Young, G. R. Baker, R. L. Potter, L. Audoly, D. Cooper, C. D. Weis, K. Morris, and C. S. Johnson, Jr., Macromolecules, 26, 2394 (1993).

20. J. K. Young, G. R. Baker, G. R. Newkome, K. F. Morris, and C. S. Johnson, Jr., Macromolecules, 27, 3464 (1994).

21. K. Lorenz, R. Mulhaupt, H. Frey, U. Rapp, and F. J.MayerPosner, Macromolecules, 28, 6657 (1995).

22. M. Chai, Z. Pi, C. Tessier, and P. L. Rinaldi, J. Am. Chem. Soc., 121, 273 (1999).

23. J. W. Kriesel, S. Konig, M. A. Freitas, A. G. Marshall, J. A. Leary, and T. D. Tilley, J. Am. Chem. Soc., 120, 12207 (1998).

24. J. Hu and D. Y. Son, Macromolecules, 31, 8644 (1998),

25. G. R. Newkome, C. N. Moorefield. G. R. Baker, A. L. Johnson, and R. K. Behera, Angew. Chem., Int. Ed. Engl., 30, 1176 (1991).

26. C. J. Hawker and J. M. J. Frechet, J. Am. Chem. Soc., 112, 7638 (1990).

27. C. J. Hawker and J. M. J. Frechet, Macromolecules, 23, 4726 (1990).

28. K. L. Wooley, C. J. Hawker, and J. M. J. Frechet, J. Am. Chem. Soc., 113, 4252 (1991).

29. V. Percec, P. Chu, G. Ungar, and J. Zhou, J. Am. Chem. Soc., 117, 11411 (1995).

30. C. J. Hawker and J. M. J. Frechet, J. Chem. Soc., Perkin Trans. 1, 2459 (1992).

31. T. M. Miller, E. W. Kwock, and T. X. Neenan, Macromolecules., 25, 3143 (1992).

32. J. W. Leon, M. Kawa, and J. M. J. Frechet, J. Am. Chem. Soc.,
118, 8847 (1996).

33. P. M. Bayliff, W. J. Feast, and D. Parker, Polym. Bull., 29, 265 (1992)

34. A. Morikawa, M. Kakimoto, and Y. Imai, Macromolecules, 25, 3247 (1992).

35. T. M. Miller, T. X. Neenan, R. Zayas, and H.E. Bair, J. Am. Chem. Soc., 114, 1018 (1992).

36. A. Morikawa, M. Kakimoto, and Y. Imai, Macromolecules, 26, 6324 (1993).

37. A. Morikawa and K. Ono, Macromolecules, 32, 1062 (1999).

38. J. S. Moore and Z. Xu, Macromolecules, 24, 5893 (1991).

39. Z. Xu, M. Kahr, K. L. Walker, C. L. Wilkins, and J. S. Moore, J. Am. Chem. Soc., 116, 4537 (1994).

40. T. Kawaguchi, K. L. Walker, C. L. Wilkims, and J. S. Moore, J. Am. Chem. Soc., 117, 2159 (1995).

41. P. Bharathi, U. Patel, T. Kawaguchi, D. J. Pesak, and J. S. Moore, Macromolecules, 28, 5955 (1995).

42. D. J. Pesak, J. S. Moore, and T. E. Wheat, Macromolecules, 30, 6467 (1997).

43. J. Louie and J. F. Hartwig, J. Am. Chem. Soc., 119, 11695 (1997).

44. M. Jayaraman and J. M. J. Frechet, J. Am. Chem. Soc., 112, 12996 (1998).

45. R. Spindler and J. M. J. Frechet, J. Chem. Soc. Perkin Trans. 1, 913 (1993).

46. F. Zeng and S. C. Zimmerman, J. Am. Chem. Soc., 118, 5326 (1996).

47. S. K. Deb, T. M. Maddux, and L. Yu, J. Am. Chem. Soc., 119, 9079 (1997)

48. E. C. Constable and A. M. W. C. Thompson, J. Chem. Soc., Chem. Commun., 617 (1992).

49. T. Nagasaki, S. Arimori, and S. Shinkai, J. Chem. Soc., Chem. Commun., 608 (1992).

50. K. R. Gopidas, A. R. Leheny, G. Gaminati, N. J. Turro, and D. A. Tomalia, J. Am. Chem. Soc., 113, 7335 (1991).

51. N. Turro, J. K. J. Barton, and D. A. Tomalia, Acc. Chem. Res., 24, 332 (1991).

52. A. Morikawa, M. Kakimoto, and Y. Imai, Polym. J., 24, 573 (1992).

53. J.-J. Lee and W. T. Ford, Macromolecules, 27, 4632 (1994).

54. G. R. Newkome, C. N. Moorefield, J. M. Keith, G. R. Baker, and G. H. Escamilla, Angew. Chem., Int. Ed. Engl., 33, 666 (1994).

55. P. J. Dandliker, F. Diederich, J.-P. Gisselbrecht, A. Louati, and M. Gross, Angew. Chem., Int. Ed. Engl., 34, 2725 (1995).

56. M. C. Coen, K. Lorenz, J. Kressler, H. Frey, and R. Mulhaupt, Macromolecules, 29, 8069 (1996).

57. C. Larre, B. Donnadieu, A.-M. Caminade, and J.-P. Majoral, J. Am. Chem. Soc., 120, 4029 (1998).

58. C. M. Cardona and A. E. Kaifer, J. Am. Chem. Soc., 120, 4023 (1998).

59. G. R. Newkome, C. N. Moorefield, G. R. Baker, M. J. Saunders, and S. H. Grossman, Angew. Chem., Int. Ed. Engl., 30, 1178 (1991).

60. S. Stevelmans, J. C. M. van Hest, J. F. G. A. Jansen, D. A. F. J. van Boxtel, E. M. M. de Brabander-van den Berg, and E. W. Meijer, J. Am. Chem. Soc., 118, 7398 (1996).

61. A. I. Cooper, J. D. Londono, G. Wignall, J. B. McClain, E. T. Samulski, J. S. Lin, A. Dobrynin, M. Rubinstein, A. L. C. Burke, J. M. J. Frechet, and J. M. DeSimone, Nature, 389, 368 (1997).

62. R. Sadamoto, N. Tomioka, and T. Aida, J. Am. Chem. Soc., 118, 3978 (1996).

63. S. W. Krska and D. Seyferth, J. Am. Chem. Soc., 120, 3604 (1998).

64. J. K. Kallitsis, F. Kakali, and K. G. Gravalos, Macromolecules, 27, 4509 (1994).

65. A. Morikawa, Macromolecules, 31, 5999 (1998).

66. P. J. Dandriker, F. Diederich, M. Gross. C. B. Knobler, A. Louati, and E. M. Sanford, Angew. Chem., Int. Ed. Engl., 33, 1739 (1994).

67. J. W. Leon and J. M. J. Frechet, Polym. Bull., 35, 449 (1995).

68. J. W. Leon, M. Kawa, and J. M. J. Frechet, J. Am. Chem. Soc., 118, 8847 (1996). 
69. G. R. Newkome, R. Guther, C. N. Moorefield, F. Cardullo, L. Echegoyen, E. Perez-Cordero, and H. Luftmann, Angew. Chem., Int. Ed. Engl., 34, 2023 (1995).

70. H. S. Sahota, P. M. Lloyd, S. G. Yeates, P. J. Derrick, P. C. Taylor, and D. M. Haddleton, J. Chem. Soc., Chem. Commum.,
2445 (1994).

71. K. L. Walker, M. S. Kahr, C. L. Wilkins, Z. Xu, and J. S. Moore, J. Am. Soc., Mass Spectrom., 5, 731 (1994).

72. K. L. Wooley, C. J. Hawker, J. M. Pochan, and J. M. J. Frechet, Macromolecules, 26, 1514 (1993). 